\title{
Stem cell therapies for reversing vision loss
}

\begin{abstract}
Current clinical trials that evaluate human pluripotent stem cell (hPSC)-based therapies predominantly target treating macular degeneration of the eyes because the eye is an isolated tissue that is naturally weakly immunogenic. Here, we discuss current bioengineering approaches and biomaterial usage in combination with stem cell therapy for macular degeneration disease treatment. Retinal pigment epithelium (RPE) differentiated from hPSCs is typically used in most clinical trials for treating patients, whereas bone marrow mononuclear cells (BMNCs) or mesenchymal stem cells (MSCs) are intravitreally transplanted, undifferentiated, into patient eyes. We also discuss reported negative effects of stem cell therapy, such as patients becoming blind following transplantation of adiposederived stem cells, which are increasingly used by 'stem-cell clinics'.
\end{abstract}

Keyword: Stem Cell; Human Pluripotent Stem Cell (hPSC); Transplants; Human induced PSC (iPSC) 